circulation via aorta. Second portion of the indicator enters lungs via $\mathrm{PA}$, then again enters SV via left atria etc. The model suggests that $\mathrm{Op} / \mathrm{Q}$ s may be calculated from dilution curve (Pic.1) Op/ Os=S2/S1.

Results COstatus monitor, (Transonic Systems Inc., NY, USA) was used in NICU and PICU patients to measures cardiac output, blood volumes and to identify shunts and PDA. According to Transonic curve data archive recoded by COstatus for single ventricle patients the actual shape of dilution curves (example, Pic.2) well agrees with model data.

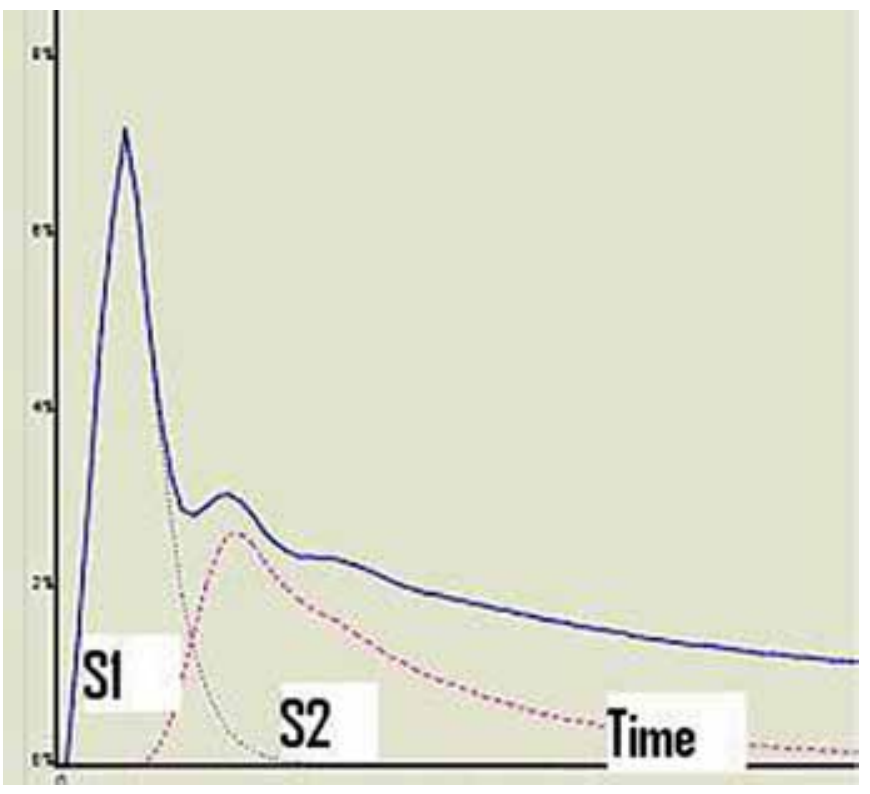

Abstract 782 Figure 1 Dilution Curve Model

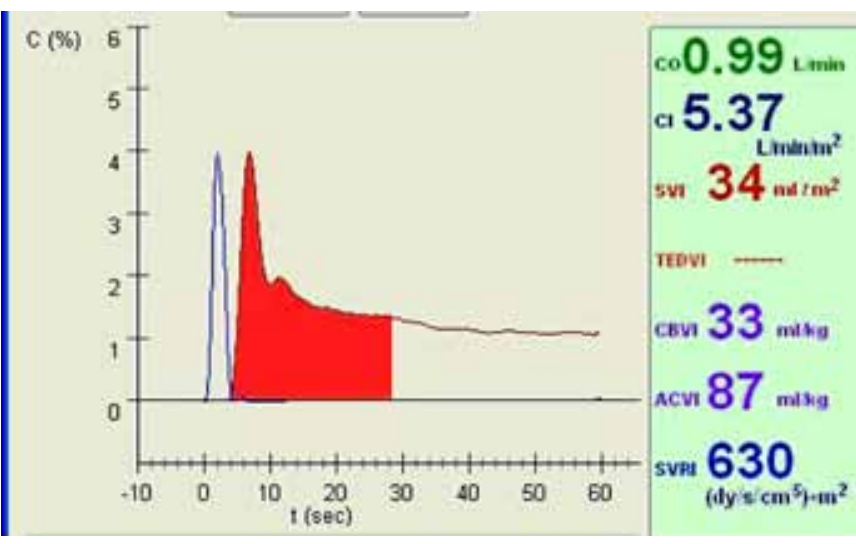

Abstract 782 Figure 2 SV Patient Dilution Curve

Conclusions Mathematical model for indicator movement in SV anatomy proved that $\mathrm{Op} / \mathrm{Os}$ value can be calculated from indicator dilution curve. Next step is to validate the $\mathrm{ap} / \mathrm{Q}$ s values measured by COstatus in animal model and in patients.

Grant NIH SBIR \# R43 HL111852-01.

\section{MANAGEMENT OF SEVERE PAEDIATRIC TRAUMA BRAIN INJURY (PTBI) GUIDED BY INTRACRANIAL PRESSURE (ICP) MONITORING IN A PICU IN ALGERIA}

doi:10.1136/archdischild-2012-302724.0783

H Bouguetof, MA Negadi, K El Halimi, D Boumendil, ZC Mentouri. Pediatric Intensive Care Unit, Faculty of Medicine - Oran University, Oran, Algeria
Background and Aims PTBI is the leading cause of death and long-term morbidity. Current recommendations for the management of severe PTBI (Glasgow Coma [GCS] score $\leq 8$ ) indicate that ICP monitoring is appropriate in infants and children (Option). The most reliable methods of ICP monitoring are ventricular catheters and intra parenchymal systems. The aim of this study is to evaluate the management of PTBI based on continues monitoring of intraparenchymal ICP in a PICU in Algeria.

Methods Between January 2005 and December 2009 we collected 308 PTBI, 57 patients had intraparenchymal ICP monitoring. The consensus is to treat ICP exceeding the $20 \mathrm{mmHg}$ threshold, and to optimize cerebral perfusion pressure (CPP).

Results The mean age was 8 years, hypoxia and hypotension were frequent at admission, median GCS after resuscitation $=6$, ICP monitoring was set up by the intensivist in the PICU after un average time of 13 hours after trauma. Intracranial hypertension was detected and treated (mannitol, hyerventilation and thiopental) in more than $90 \%$ of cases. the average time of ICP monitoring was 5 days. No complications (infection, hemorrhage) with this technique was detected.

Conclusion The etiology and the pathophysiology of raised ICP in PTBI is a complex challenge for the intensivist. CPP and ICP were the first brain-specific targets for goal-directed therapies enacted in PTBI. In this study, ICP monitoring allows to detect intracranial hypertension and guide treatment better than when this technique is absent even if it is not a standard of the recommendations.

\section{SEEKING FOR DEFINITIONS OF POOR PERFUSION STATES (PPS) IN LOW BIRTH WEIGHT INFANTS (LBWI) (PART I)}

doi:10.1136/archdischild-2012-302724.0784

'MC Bravo, 'P López-Ortego, 'L Sánchez, 2J Riera, 'F Cabañas, E Pérez-Fernández, 'J Quero, 'A Pellicer. 'La Paz University Hospital, Department of Neonatology; ${ }^{2}$ BioEngineer and Nanotechnology Department, Polytechnic University of Madrid; ${ }^{3}$ Division of Statistics, La Paz University Hospital, Madrid, Spain

Background and Aims Echocardiography-derived low superior vena cava flow (SVCF) associates intraventricular haemorrhage, neurodisability and death. The weaknesses of the method relate to its variability. We aim to explore the relationship between two SVCF cut-off values to define PPS in LBWI and the patients' shortterm neonatal co-morbidities.

Methods One hundred LBWI [27.4 (2) wks; 1014 (316) g] who reached illness score below threshold, underwent early $(<12 \mathrm{~h})$ and serial echocardiography for the first $96 \mathrm{hs}$ after birth. The primary outcome was low SVCF prevalence according to two thresholds: < $41 \mathrm{ml} / \mathrm{k} / \mathrm{min}$ and $[<41 \mathrm{ml} / \mathrm{k} / \mathrm{min}$ + SVCF repeatability index (RI)] ( $\mathrm{RI}$ is twice the standard deviation of the differences divided by the mean of all the measures). Secondary outcomes were short-term neonatal clinical outcomes in relation to SVCF status.

Results $\mathrm{SVCF}<41 \mathrm{ml} / \mathrm{k} / \mathrm{min}$ prevalence was $30 \%$ and was associated with immaturity $(\mathrm{p}=0.02)$, corioamnionitis (0.007), advanced resuscitation at birth (0.004), lower Apgar scores $(\mathrm{p}<0.01)$ and postnatal ischemic events (bowel perforation or arterial vasospasm) $(\mathrm{p}=0.002)$. At SVCF $<51 \mathrm{ml} / \mathrm{k} / \mathrm{min}(41 \mathrm{ml} / \mathrm{k} / \mathrm{min}+$ repeatability index) cut-off value, the PPS prevalence was $50 \%$; in addition to the above-mentioned co-morbidities trends showed an association between PPS and combined adverse outcome (death or intracranial haemorrhage).

Conclusions Low SVCF is highly prevalent in the sick LBWI during the early postnatal period. The association of low SVCF with ischemic events and adverse outcome supports this biomarker as an indicator of PPS.

Disclaimer No conflict of interest. Study supported by the Spanish Health Ministry, SAS/2481/2009, the SAMID network (RD08/0072/0018). 
785 SINGLE-CENTER EXPERIENCE WITH LEVOSIMENDAN AS AN ALTERNATIVE TO CATECHOLAMINE IN CHILDREN WITH SEVERE CATECHOLAMINE DEPENDENT END-STAGE HEART FAILURE

doi:10.1136/archdischild-2012-302724.0785

F Alsohime. Louis Pradel Hospital, Lyon, France

Objective To describe our preliminary experience with Levosimendan during the last 4 years, a new calcium-sensitizing agent in critically unwell infants and children with severe heart failure.

Design Retrospective cohort analysis.

Setting Pediatric cardiology intensive care unit.

Patients 8 children aged 2.5 months to 13 yrs (median age 44 months) with severe myocardial dysfunction secondary to endstage heart failure who were inotropedependent (requiring at least one catecholamine).

Interventions A single dose (continuous intravenous infusion over $24 \mathrm{hrs}$ ) of Levosimendan was given under continuous hemodynamic monitoring in our intensive care unit.

Six children received a single dose, two children received two doses,

Echocardiographic assessments of ventricular function were made before and 3-5 days after Levosimendan infusion.

Measurements and Main Results Heart rate, systolic pressure, diastolic pressure, mean blood pressure, shortening fraction, the dose of inotrope at the beginning of levosimendan infusion, at 24 hours and 36 hours, ECG result 24 hour after levosimendan infusion.

Conclusions Levosimendan appeared to be a safe and efficacious drug when given to children with uncompensated end-stage heart failure in this size-limited sample. It warrants formal prospective large-cohort evaluation and multicenter trial to determine its safety profile and clinical application in the pediatric population.

\section{LOW PLATELET COUNT IS ASSOCIATED WITH DUCTUS ARTERIOSUS PATENCY IN PRETERM NEWBORNS}

doi:10.1136/archdischild-2012-302724.0786

E Alyamac Dizdar, R Ozdemir, FN Sari, S Yurttutan, T Gokmen, 0 Erdeve, FE Canpolat, N Uras, SS Oguz, U Dilmen. Neonatal Intensive Care Unit, Zekai Tahir Burak Maternity and Teaching Hospital, Ankara, Turkey

Background and Aims To determine whether there is an association between platelet counts and patent ductus arteriosus (PDA) incidence and/or closure in preterm newborns.

Methods Premature infants with hemodynamically significant PDA $(n=154)$ and a control group without PDA $(n=207)$ who were hospitalized in the NICU were eligible. Platelet counts and other platelet indices including mean platelet volume (MPV) and platelet distribution width (PDW) of the infants in both groups during the first 3 days of life were recorded. Ibuprofen was started in infants with hemodynamically significant PDA and echocardiography was repeated 48 hours thereafter to assess the closure of ductus.

Results Median gestational age and birth weight of the infants with PDA were 28 (range 26-29) weeks and 1060 (range 892-1250) gr respectively. Platelet counts were significantly lower in the patient group than in the control group $(p<0,001)$. Multivariate analysis including gestational age, presence of RDS, presence of thrombocytopenia and PDW showed that platelet count $<150.000$ (OR=2.13, 95\% CI 1.26-3.61; $\mathrm{p}=0.005)$, high PDW $(>17)(\mathrm{OR}=2.68,95 \% \mathrm{CI}$ $1.41-5.09 ; \mathrm{p}=0.003)$ and the presence of $\mathrm{RDS}(\mathrm{OR}=2.25,95 \% \mathrm{CI}$ 1.41-3.59; $\mathrm{p}=0.001$ ) were independently associated with higher risk of hemodynamically significant PDA. Baseline platelet counts of the infants in whom ductus closed or persisted after ibuprofen treatment were similar.

Conclusions Low platelet count was associated with ductus arteriosus patency in preterm infants while other platelet indices were not. We could not show an association between platelet counts and persistence or closure after medical treatment.

\section{WHAT IS THE EFFECT PDA AND ITS MEDICAL CLOSURE ON CEREBRAL AND ABDOMINAL TISSUE OXYGENATION IN PRETERM NEWBORNS?}

doi:10.1136/archdischild-2012-302724.0787

E Ergenekon, I Hirfanoglu, S Beken, N Altuntas, E Kazancı, S Unal, F Kulalı, S Aktas, E Onal, C Turkyılmaz, E Koc, Y Atalay. Pediatrics/Newborn Medicine, Gazi University Hospital, Ankara, Turkey

Background and Aim Patent ductus arteriosus (PDA) is a frequent problem in preterms known to have significant effects on organ perfusion. The aim of this study was to investigate the difference between cerebral and abdominal tissue oxygenation index (TOI) measured by near infrared spectroscopy (NIRS) before and after treatment of hemodynamically significant PDA in preterm newborns.

Methods Cerebral and abdominal TOI were recorded by NIRS (NIRO 200 Hamamatsu, Japan) in preterm newborns with hemodynamically significant PDA requiring ibuprofen treatment. Newborns with congenital anomalies were excluded. 20 minute recordings were obtained before treatment and after documented ductal closure by echocardiography as well as real time oxygen saturation $\left(\mathrm{SaO}_{2}\right)$ monitoring by pulse oxymetry. Fractional tissue oxygen extraction (FTOE) was calculated using $\mathrm{TOI}$ and $\mathrm{SaO}_{2}$.

Results Fourteen newborns were included, abdominal recordings were available in 13. Mean BW and GA were $1089 \mathrm{~g}$ and 29 weeks respectively. No change was observed in cerebral or abdominal tissue oxygenation and oxygen extraction before and after medical closure of PDA. Pre and posttreatment cerebral TOI values (median and range) were 67.17 (50.9-89.1) and 64.35 (54.9-87.4) $\mathrm{P}=0.3$, and pre and posttreatment cerebral FTOE values were $0.3(0.03-0.45)$ and $0.29(0.05-0.42) \mathrm{p}=0.09$ respectively. Pre and postreatment abdominal TOI values were (median and range) 53.9 (40.1-62.9) and 50.29 (39.2-78.5) $\mathrm{P}=0.7$, pre and posttreatment abdominal FTOE values were $0.44(0.32-0.59)$ and $0.46(0.2-0.6) \quad p=0.8$ respectively.

Conclusion Results of this small group may suggest that cerebral and abdominal tissue oxygenation is preserved during hemodynamically significant PDA, however more detailed studies are warranted.

\section{FETAL HYPOXIA-ISCHEMIA IS RELATED TO CIRCULATORY COMPROMISE IN PRETERM INFANTS}

doi:10.1136/archdischild-2012-302724.0788

'DC Vijlbrief, 'MJNL Benders, ${ }^{2} \mathrm{H}$ Kemperman, ' $\mathrm{F}$ van Bel, 'WB de Vries. 'Neonatology; ${ }^{2}$ Clinical Chemistry and Hematology, Wilhelmina Children's Hospital/University Medical Center Utrecht, Utrecht, The Netherlands

Background and Aims Impairment of gas exchange and blood flow through the placenta leads to hypoxia and hypercapnia. This causes increased systemic vascular resistance and tachycardia, thus compromising the cardiovascular system of the foetus. The biomarker B-type natriuretic peptide (BNP) can be used to identify significant cardiovascular compromise in infants. The aim of the present study was to investigate whether BNP can be used to identify those preterm infants with significant cardiovascular compromise during peripartum period.

Methods In this retrospective cohort study all infants born after a gestational age of less than 32 weeks were evaluated. Maternal, fetal and infant factors associated with prenatal and perinatal hypoxiaischemia were related to BNP levels after birth. Pathologic examination of the placenta was routinely performed. 